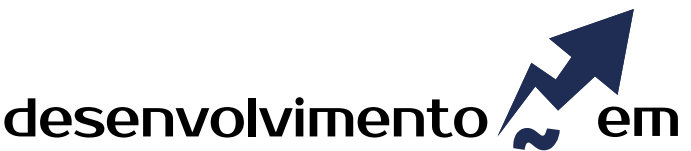 QUESTÂOO
}

\section{Agenda Governamental: \\ Influências na sua construção nos municípios integrantes da 31a Secretaria de Desenvolvimento Regional de Itapiranga - SC}

\author{
http://dx.doi.org/10.21527/2237-6453.2018.45.63-81 \\ Recebido em: 10/3/2016 \\ Aceito em: $14 / 4 / 2018$
}

Ari Söthe ${ }^{1}$, Oklinger Mantovaneli Junior ${ }^{2}$, Patricia Luiza Kegel ${ }^{3}$

\begin{abstract}
RESUMO:
A construção das agendas governamentais com a participação dos diversos atores precede o planejamento das políticas públicas. Diante disso, o presente artigo busca descrever a influência dos diferentes eventos, atores e questões na elaboração da agenda dos municípios integrantes da região de abrangência da 31a Secretaria de Desenvolvimento Regional (SDR) de Itapiranga - SC. Inicialmente por meio da fundamentação teórica foram abordados os principais conceitos sobre políticas públicas e agenda governamental e seus diversos atores. Posteriormente foi realizada uma pesquisa descritiva e exploratória, de abordagem qualitativa, de levantamento por meio de entrevistas nos municípios pesquisados. A descrição dos dados evidencia que os entrevistados visualizam as agendas governamentais como mecanismo fundamental na definição das ideias que devem prevalecer e integrar os planos do governo. Denota-se que a mídia tem influência sobre os diversos atores que participam do planejamento e estabelecimento das agendas. Infere-se que a agenda pública é influenciada pelas demandas imediatas e setoriais. Por outro lado, a agenda de políticas governamentais é influenciada por distintos eventos, como frustrações de receitas, judicialização de políticas, agenda eleitoral, entre outros. O fluxo das questões na construção da agenda governamental tem uma pequena capacidade de competição, seu sucesso ocorre em razão da força dos atores e disponibilidade de recursos. As questões são influenciadas pela sua compreensão como problema e suas possíveis soluções, assim como, em alguns casos, pelas barganhas políticas. Conclui-se que diversos atores, como a mídia, políticos, lideranças, Judiciário, Conselhos e os próprios agentes do governo são influentes no processo de elaboração das agendas.
\end{abstract}

Palavras-chave: Agenda governamental. Políticas públicas. Atores. Municípios.

\section{GOVERNMENT AGENDA: INFLUENCES IN YOUR BUILDING IN MUNICIPAL MEMBERS OF 31TH DEPARTMENT OF REGIONAL DEVELOPMENT ITAPIRANGA - SC}

\section{ABSTRACT:}

The construction of government agendas with the participation of different actors precedes the planning of public policies. Thus, this article aims to describe the influence of different events, actors and issues in the construction of the agenda of the municipalities of the region covered by the 31th Department of Regional Development (DRD) of Itapiranga - SC. Initially through the theoretical foundation were discussed the main concepts of public policy and government agenda and its various stakeholders. Subsequently, a descriptive survey was conducted with a qualitative approach, survey through interviews with the surveyed municipalities. The description of the data shows that respondents view their municipal agendas as a key mechanism in the definition of ideas must prevail and integrate government plans. Denotes that the media has an influence on the various actors participating in the planning and implementation of agendas. It is inferred that the public agenda is influenced by immediate and sectorial demands. On the other hand, the agenda of government policy is influenced by several events as revenue frustrations, policy judicialization, electoral agenda, among others. The flow of the issues in the construction of government agenda has a little competition, its success is due to the strength of the actors and resource availability. The issues are influenced by their understanding as a problem and possible solutions, as well as, in some cases by political bargains. In conclusion, several actors such as the media, politicians, leaders, judiciary, counsel and government agents themselves are influential in developing the agendas process.

Keywords: Government agenda. Public policy. Actors. Municipalities.

\footnotetext{
${ }^{1}$ Doutor em Desenvolvimento Regional pela Universidade Regional de Blumenau. Professor da Universidade Federal da Fronteira Sul. ari. sothe@uffs.edu.br

${ }^{2}$ Doutor em Sociologia pela Universidade Estadual Paulista Júlio de Mesquita Filho. Professor do Programa de Pós-Graduação em Desenvolvimento Regional da Universidade Regional de Blumenau. oklinger@furb.br

${ }^{3}$ Doutora em Direito pela Universidade Federal de Santa Catarina. Professora do Programa de Pós-Graduação em Desenvolvimento Regional da Universidade Regional de Blumenau. plkegel@yahoo.com.br
} 
A ampliação da transparência e participação da sociedade na administração pública inicia-se com a construção da agenda governamental, conhecida como agenda setting. Para Capella (2005), a agenda setting é o processo de competição de ideias para ganhar espaço diante da mídia, do público e dos altos escalões governamentais.

A mídia é um agente importante como focalizador para os atores que não têm poder de decisão e precisam atrair a atenção dos formuladores das políticas (KINGDON, 2003). Rossetto e Silva (2012, p. 99) ressaltam que "os assuntos colocados em pauta pelos meios de comunicação de massa agendam o público, chegando a tornar-se tema de suas conversas cotidianas". De outro modo, os altos escalões governamentais são centrais no processo de agenda setting, apesar de possuírem menor controle sobre 0 processo que o chefe do Executivo (CAPELLA, 2005).

Entre os atores influentes na definição da agenda governamental merecem destaque os atores visíveis, como o presidente, ministros, senadores, deputados, partidos políticos, grupos de interesse, participantes do processo eleitoral, mídia e opinião pública. Por outro lado, os atores invisíveis exercem maior influência na definição de alternativas para a agenda e correspondem aos servidores públicos, analistas de grupos de interesse, assessores parlamentares, acadêmicos, pesquisadores e consultores (CAPELLA, 2004).

Para explicar a formação e mudanças nas agendas governamentais de políticas públicas são conhecidos os modelos de Kingdon (2003) e Baumgartner e Jones (1993). “Estes modelos representam importantes ferramentas na análise de processos de formulação de políticas e de mudança na agenda governamental, reservando grande destaque à dinâmica das idéias no processo político" (CAPELLA, 2005, p. 2).

Viana (1996) destaca que autores como Hofferbert (1974) e Cobb e Elder (1971) já discutiam as fases da elaboração da agenda governamental de políticas públicas. Esses autores tentavam explicar, entre outros, porque alguns itens ou assuntos são selecionados para deliberação governamental e outros não, assim como porque os cidadãos não querem saber e fazer parte da ação governamental.

Outro estudo pertinente foi realizado por Pinto (2008) com o objetivo de analisar a incorporação das propostas gerencialistas e de gestão dos hospitais públicos por meio de organizações sociais, no contexto de um dos Estados brasileiros, a Bahia. Para tanto focalizou na construção da agenda política pública no aspecto de tomada de decisão. Identificou a importância de eleger o modelo de Kingdon para a compreensão dos momentos e dos elementos que compõem o processo, ou seja, os momentos de "pré-decisão" e de "decisão", e os atores, arenas, problemas e alternativas de políticas que se constituem em objeto do processo decisório.

Entre os estudos mais recentes, merece destaque o de Costa Filho e Rezende (2016), que analisaram o fluxo e ascensão dos serviços de abastecimento de água à agenda governamental no município de Rio Branco - Acre. Igualmente foi fundamentado no modelo dos fluxos múltiplos de Kingdon. Seus resultados indicam a existência de uma situação grave no fluxo de problemas, criando-se reais oportunidades para a sua entrada na agenda. Verificou-se também que a abertura da janela de oportunidade para o saneamento foi viabilizada pela presença, na região, do Serviço Especial de Saúde Pública - Sesp - e posteriormente da Fundação Serviço Especial de Saúde Pública - FSESP. 
Esse estudo difere dos anteriores, pois, diante de um cenário de intervenção dos diferentes atores para o planejamento e instituição das políticas públicas, em especial as municipais, busca solucionar a seguinte questão de pesquisa: Qual a influência dos diferentes eventos, atores e questões no planejamento e efetivação de políticas púbicas dos municípios integrantes da região de abrangência da 31a Secretaria de Desenvolvimento Regional (SDR) de Itapiranga - SC?

A partir da questão de pesquisa pressupõe-se que os diferentes eventos, atores e questões são capazes de influenciar as agendas, assim como a influência das agendas sobre o planejamento e instalação de políticas públicas locais.

Para atingir o objetivo do estudo foi realizada uma pesquisa exploratória e descritiva, com utilização de fontes primárias, coleta de dados por levantamento e de abordagem qualitativa. Para tanto foram aplicadas entrevistas estruturadas aos responsáveis pelo processo de coordenação da agenda dos municípios objeto de estudo. A amostra selecionada foi do tipo intencional e por acessibilidade.

O estudo procura contribuir na identificação da importância dos eventos, atores e questões no planejamento e estabelecimento das políticas públicas nos municípios. Justifica-se e passa a ser relevante com sua capacidade de estimular e demonstrar a transparência dos municípios no processo de planejamento e prática das políticas públicas. De outro modo, permite evidenciar os municípios em que determinados eventos e atores se destacam por sua influência nesses processos, possibilitando que os formuladores das políticas venham a reavaliar o planejamento e efetivação de políticas em função dessa influência.

O estudo é constituído de cinco seções, iniciando com essa introdução. Posteriormente apresenta a fundamentação teórica que sustenta a pesquisa. Em seguida são expostos os procedimentos metodológicos utilizados para realizar a pesquisa. Na sequência é feita a descrição e interpretação dos dados coletados. Finalizando o estudo, são apresentadas as conclusões do estudo e recomendações dentro do que abrange o tema investigado.

\section{FUNDAMENTAÇÃO TEÓRICA}

\section{Políticas públicas}

As políticas públicas compreendem ao conjunto de mecanismos de que o Estado lança mão para fazer valer seus objetivos. "Isto é, o modo de operar do Estado, que se traduz no ato de 'fazer' políticas públicas" (VIANA, 1996, p. 1). O campo de conhecimento que poderíamos denominar de políticas públicas ganha significativa importância nas últimas décadas, bem como os seus modelos de elaboração, decisão, instalação e avaliação. Entre os diversos fatores que aumentaram a sua visibilidade estão a adoção de políticas restritivas de gastos, em especial nos países em desenvolvimento, que passaram a dar maior importância ao processo de execução de políticas econômicas e sociais (SOUZA, 2006). Esse novo cenário começa a atribuir maior importância às políticas postas em prática, principalmente diante da necessidade do equilíbrio fiscal e consequente limitação da intervenção do Estado como agente de viabilização de políticas públicas. 
Boisier (2000) destaca que as políticas públicas tendem a melhorar a qualidade e cobertura de vários aspectos importantes da vida em sociedade, como a educação, a saúde, incentivos tributários para fomentar a capacitação laboral, flexibilização do mercado de trabalho e abertura ao comércio exterior. É por meio das políticas públicas que os governos buscam melhorar a vida dos cidadãos, redistribuindo renda e atendendo às demandas sociais. Nesse sentido, Silva e Bassi (2012) destacam que o amadurecimento do Estado depende de gestores e políticas públicas que estimulem a inclusão da população, como cidadão digno e capaz de tomada de decisão e que contribua para o desenvolvimento. O planejamento e a execução de políticas públicas partem da identificação de necessidades da sociedade e vinculação das possíveis soluções com a intervenção do Estado. "A implantação das políticas públicas passa pela compreensão de que existem cenários e interesses diversos, atores díspares, levando a configuração de que a política pública passa por diversas etapas até sua efetiva implementação" (WEEGE, 2012, p. 37). Assim, os governos munidos do poder e estrutura estatal tornam-se legítimos representantes do cidadão para acolher as demandas sociais e instituí-las a partir das prioridades definidas em suas agendas.

Em outra linha de pensamento, Costa (2008) ressalta que o modelo de Cohen, March e Olsen (1972), conhecido como "lata de lixo", explica a forma de tomada de decisão em políticas públicas. Esse modelo lista três propriedades que integram o processo. Inicialmente apresenta a denominada participação fluida da troca frequente de dirigentes governamentais e atores envolvidos com a tomada de decisão. A segunda propriedade compreende a deficiência dos atores em elencar suas preferências, que nem sempre sabem quais são os objetivos envolvidos e como poderão ser atingidos. A última propriedade é que a tecnologia para as políticas públicas não é claramente conhecida, não se sabendo com exatidão os procedimentos e atores que terão alguma participação para a tomada de decisão na definição da política.

Dessa forma, o modelo da "lata de lixo" é perfeitamente aplicável no cenário local, quando a elaboração da agenda de políticas públicas torna possível o encontro dos três elementos centrais que compreendem ao problema, solução e momento político.

No que se refere ao ciclo das políticas públicas, Frey (2000, p. 226) apresenta as fases do ponto de vista analítico, compreendendo a "percepção e definição de problemas, 'agenda-setting', elaboração de programas e de decisão, implementação de políticas e, finalmente, a avaliação de políticas e a eventual correção da ação". No Quadro 1 são descritos os procedimentos realizados em cada uma dessas fases.

Quadro 1 - Fases e procedimentos do ciclo das políticas públicas

\begin{tabular}{|c|l|}
\hline Fase & \multicolumn{1}{|c|}{ Procedimento } \\
\hline $\begin{array}{c}\text { Percepção e definição de proble- } \\
\text { mas }\end{array}$ & $\begin{array}{l}\text { Percepção por parte de grupos sociais, políticos, grupos de políti- } \\
\text { cos ou pela administração pública de um fato como um problema } \\
\text { político. }\end{array}$ \\
\hline $\begin{array}{c}\text { Agenda-setting } \\
\text { Elaboração de programas e de } \\
\text { decisão }\end{array}$ & $\begin{array}{l}\text { Decisão se um tema vem sendo inserido na pauta política atual, se } \\
\text { o tema deve ser excluído ou adiado para uma data posterior. }\end{array}$ \\
\hline Implementação de políticas & Fase em que a encomenda de ação é estipulada. \\
\hline $\begin{array}{c}\text { Avaliação de políticas e da corre- } \\
\text { ção de ação }\end{array}$ & $\begin{array}{l}\text { Fase em que se apreciam os programas já implementados no no to- } \\
\text { cante a seus impactos efetivos. }\end{array}$ \\
\hline
\end{tabular}

Fonte: Elaborado com base em Frey (2000, p. 227-228). 
Constata-se por meio do Quadro 1 que um problema social ganha importância política a partir do momento em que é compreendido como demandante de política pública. Posteriormente, o tema passa a integrar a agenda-setting quando considerado viável na relação de custos e benefícios e suas chances na pauta política (FREY, 2000).

A decisão de qual programa deve prevalecer ocorre a partir da capacidade de influência dos atores envolvidos e no processo de negociação entre eles. Já a instauração de políticas pode divergir com os resultados da fase anterior, devido à diferença entre os impactos reais com os projetados. Finalmente a fase da avaliação das políticas e correção de ações busca identificar os impactos negativos e seus efeitos indesejados, o que permite visualizar as consequências para ações e programas futuros (FREY, 2000).

Diante disso, no tópico a seguir veremos como os problemas levantados pelos diferentes atores passam a incorporar a agenda governamental e se materializam como política pública.

\section{Agenda governamental e seus atores}

A agenda de políticas governamentais é construída a partir de questões relevantes para os formuladores das políticas. Capella (2004) destaca que os estudos sobre agenda-setting frequentemente apontam para três campos de análise, compreendendo: a) as questões emergentes na agenda da mídia influenciam diretamente a agenda pública, com abrangência também na agenda governamental; b) os temas da agenda pública materializam-se na agenda governamental e provocam efeitos na agenda midiática; c) questões geradas na agenda governamental exercem influência na agenda da mídia e agenda pública. Percebe-se que nenhuma das agendas é construída isoladamente, mas que existe algum grau de interferência entre elas.

Para Kingdon (2003), a agenda governamental compreende o conjunto de aspectos que o governo e pessoas a ele ligadas concentram sua atenção num determinado momento.

As condições apresentadas em determinado momento "podem chamar a atenção dos formuladores de políticas, transformando-se em problemas, e posteriormente alcançar a agenda governamental" (CAPELLA, 2005, p. 5).

De acordo com Pinto (2008, p. 16), "a agenda governamental é determinada nas correntes políticas ou de problemas, e as alternativas são geradas na corrente de política pública". Isso demonstra que a agenda de políticas públicas forma-se a partir de um cenário de problemas acompanhado de alternativas de solução. Essas soluções são apresentadas pelos empreendedores que esperam pelo momento em que "janelas de problemas ou janelas de políticas" se abrem, obtendo sucesso quando as correntes de problemas, alternativas e política estiverem unidas, proporcionando a abertura de uma janela para a política pública.

Gottems et al. (2013, p. 513) definem que

a agenda governamental segue um processo não intencional que se caracteriza por: 1) surgimento ou reconhecimento de um problema pela sociedade em geral; 2) existência de ideias e alternativas para conceituá-los - originadas de especialistas, investigadores, políticos e atores sociais, dentre outros; 3 ) contexto político, administrativo e legislativo favorável ao desenvolvimento da ação. 
O fluxo dos problemas ocorre a partir do reconhecimento de questões como fatos que devem compor a agenda do governo, apresentando-se motivos para tal, como: a) sua magnitude; b) ocorrência dos eventos (crises, desastres, etc.) (CAPELLA, 2005); c) a capacidade de solução dentro do orçamento, custos e gastos. É relevante nesse processo a percepção por parte dos formuladores de políticas públicas da importância do evento ou realidade presente.

De outra forma, as alternativas de solução ao problema são apresentadas por um conjunto de ideias, em que algumas se mantêm e outras desaparecem, a partir de fatores como confiabilidade, aceitabilidade, compatibilidade e capacidade.

Finalmente o ambiente favorável, compreendido pelo clima nacional, forças políticas e mudanças no governo é que permite a formação de uma agenda política.

A Figura 1 apresenta o modelo de múltiplos fluxos de Kingdon, com a reunião dos fluxos pelos empreendedores quando as janelas de oportunidade se abrem.

Figura 1 - Modelo de Kingdon

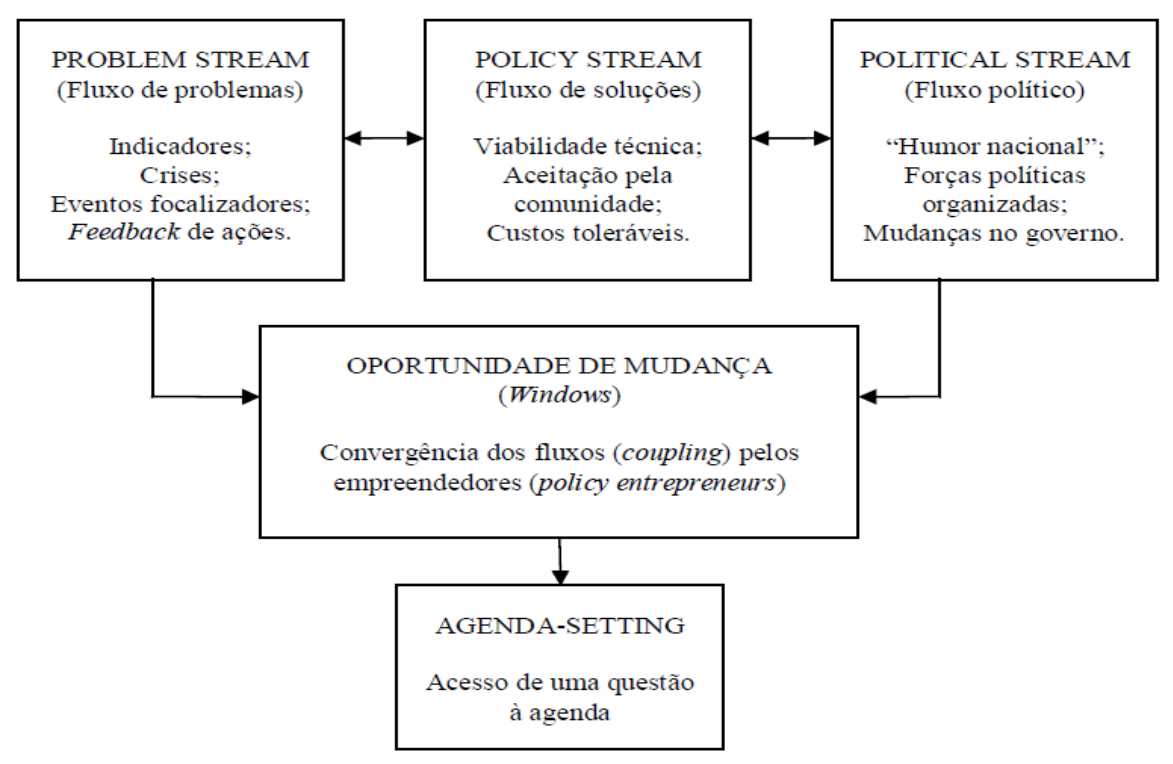

Fonte: CAPELLA (2004, p. 32)

A agenda governamental é construída a partir das questões que conseguem chegar até ela, conforme demonstrado pelo modelo de Kingdon. Entre os atores que interferem para que a questão chegue até a agenda, Viana (1996) divide-os em dois grupos: os governamentais e os não governamentais.

Os atores governamentais são constituídos pelo "alto staff! da administração (presidente, staff! do Executivo e políticos nomeados para cargos públicos); pelo funcionalismo de carreira; e, finalmente, pelos parlamentares e funcionários do Congresso" (VIANA, 1996, p. 8). O autor complementa que a alta administração é indispensável para a elaboração da agenda e menos importante na especificação das alternativas e instituição das políticas formuladas. De outro modo, os funcionários de carreira são indispensáveis para especificar as alternativas na fase de estabelecimento das políticas e não possuindo influência na elaboração da agenda. Distante do que é apresentado por Viana (1996), percebe-se na prática que os fun- 
cionários de carreira influenciam a elaboração da agenda governamental de forma indireta, pois, acabam apresentando as alternativas não somente na fase de instalação, como também interferem na definição das prioridades a partir de diversos argumentos técnicos, jurídicos e políticos no momento da formulação da agenda. Finalmente os parlamentares e funcionários do congresso podem influenciar na agenda devido a sua autoridade legal, acesso à publicidade e longa experiência na atividade política (VIANA, 1996).

Os atores não governamentais compreendem grupos de pressão ou interesse, acadêmicos, pesquisadores e consultores, mídia, participantes das campanhas eleitorais, partidos políticos e opinião pública. Os grupos de pressão agem no processo de bloqueio e promoção de questões. Os acadêmicos buscam a especificação de alternativas com atuação de longo prazo. O terceiro ator desse grupo compreende a mídia, que exerce influências regionais e localizadas. Por fim, os partidos e a opinião pública têm grande influência na formação da agenda (VIANA, 1996).

\section{MÉTODO E PROCEDIMENTOS DA PESQUISA}

\section{Delineamento da Pesquisa}

Este estudo é classificado quanto aos seus objetivos como exploratório e descritivo. Raupp e Beuren (2004, p. 80) destacam que "uma característica interessante da pesquisa exploratória consiste no aprofundamento de conceitos preliminares sobre determinada temática não contemplada de modo satisfatório anteriormente". Por outro lado, a pesquisa descritiva analisa as características de determinada população ou fenômeno ou o estabelecimento de relações entre variáveis (GIL, 2002).

$\mathrm{Na}$ abordagem do problema, a pesquisa caracteriza-se como qualitativa. Richardson $(1989$, p. 80) afirma que "os estudos que empregam uma metodologia qualitativa podem descrever a complexidade de determinado problema, analisar a interação de certas variáveis, compreender e classificar processos dinâmicos vividos por grupos sociais".

Quanto aos procedimentos utilizados a pesquisa é classificada como de levantamento. "As pesquisas deste tipo caracterizam-se pela interrogação direta das pessoas cujo comportamento se deseja conhecer" (GIL, 2002, p. 50).

O instrumento utilizado para a realização da investigação foi a entrevista, aplicada diretamente aos responsáveis pelo processo de coordenação da agenda de políticas governamentais dos municípios integrantes da 31a Secretaria de Desenvolvimento Regional (SDR) de Itapiranga - SC, no período de 21 de outubro a 4 de novembro de 2015. Lakatos e Marconi (1992) chamam a atenção para o fato de que esse tipo de técnica “[...] é uma conversação efetuada face a face, de maneira metódica; proporciona ao entrevistador, verbalmente, a informação necessária".

A entrevista utilizada foi do tipo padronizada ou estruturada, que integra um roteiro previamente estabelecido e busca: a) identificação do entrevistado; b) conhecimento que possui quanto à importância da agenda governamental; c) influência das agendas, midiática (media agenda-setting), pública (public agenda-setting), de políticas governamentais (policy agenda-setting) e, d) competição das questões dentro do modelo dos múltiplos fluxos de Kingdon na elaboração da agenda governamental (agenda-setting). 
Diante das limitações do presente artigo, recomenda-se para futuras pesquisas a ampliação da amostra, possibilitando identificar se os resultados encontrados estendem-se aos demais municípios do Estado.

\section{Identificação dos municípios e entrevistados da pesquisa}

Com o objetivo de caracterizar os municípios definidos na população e amostra, identifica-se nesta seção a sua localização, alguns dos seus indicadores econômicos, sociais e culturais.

Na Figura 2 é apresentada a população da pesquisa, compreendida pelas 36 Secretarias de Desenvolvimento Regional (SDRs) do Estado de Santa Catarina, com destaque para a amostra correspondente aos municípios integrantes da 31a SDR de Itapiranga - SC.

Figura 2 - Mapa da abrangência das Secretarias de Desenvolvimento Regional do Estado de Santa Catarina

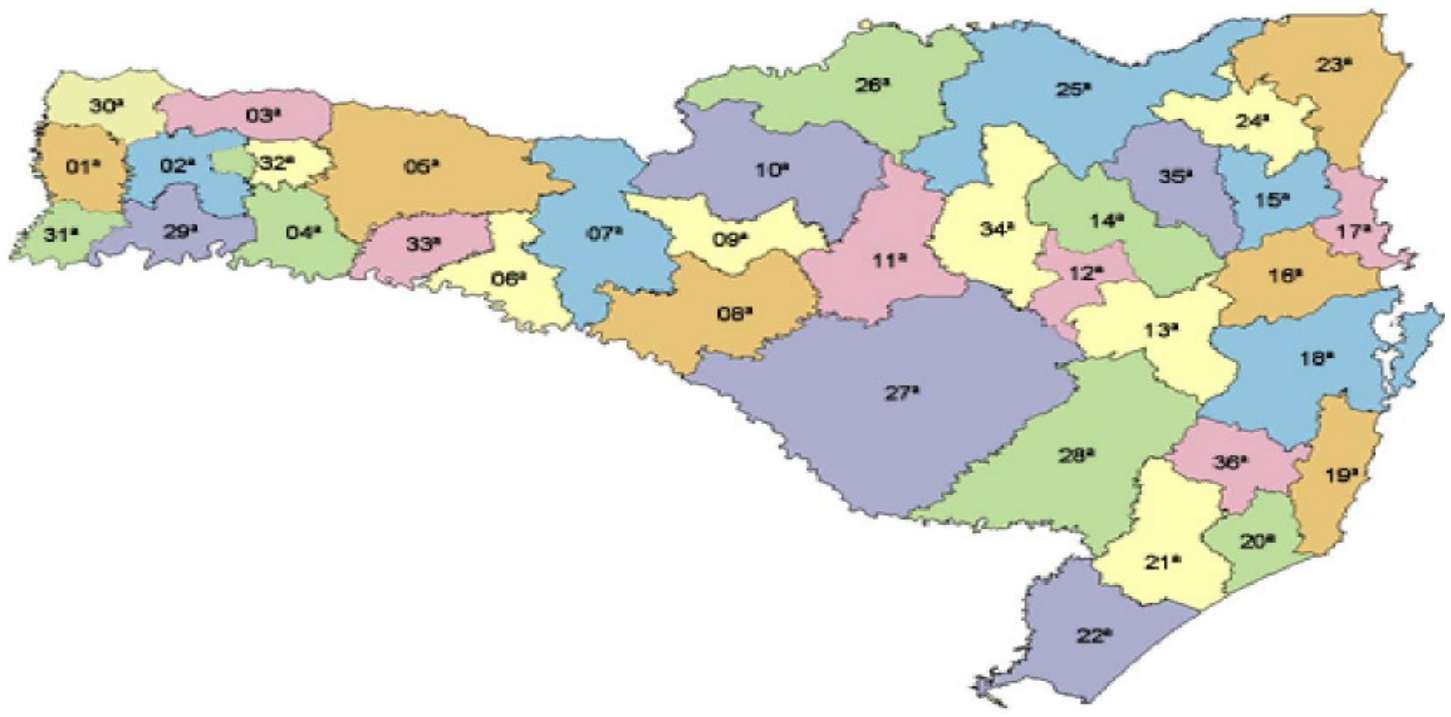

Fonte: Adaptado de: <http://portalses.saude.sc.gov.br>.

No Quadro 2 são identificados os participantes da pesquisa e suas principais características, indicadores econômicos, culturais e sociais.

Quadro 2 - Caracterização dos objetos de pesquisa

\begin{tabular}{|c|c|c|c|c|c|}
\hline Descrição & Iporã do Oeste & Itapiranga & Santa Helena & São João do Oeste & Tunápolis \\
\hline População (2010) & 8.409 & 15.409 & 2.382 & 6.036 & 4.633 \\
\hline Colonização & Alemã e Italiana & Alemã & $\begin{array}{c}\text { Italiana e Ale- } \\
\text { mã }\end{array}$ & Alemã & Alemã \\
\hline $\begin{array}{c}\text { PIB (per capita) a } \\
\text { preços correntes } \\
-2012\end{array}$ & $15.549,96$ & $20.507,82$ & $15.585,13$ & $24.857,89$ & $15.802,66$ \\
\hline $\begin{array}{c}\text { Base da Economia } \\
\begin{array}{c}\text { Índice de } \\
\text { Desenvolvimento } \\
\text { Humano }\end{array}\end{array}$ & Agropecuária & $\begin{array}{c}\text { Agrope- } \\
\text { cuária }\end{array}$ & Agropecuária & Agropecuária & $\begin{array}{c}\text { Agropecuá- } \\
\text { ria }\end{array}$ \\
\hline \begin{tabular}{c} 
Municipal - 2010 \\
\hline
\end{tabular} & 0,759 & 0,775 & 0,727 & 0,761 & 0,752 \\
\hline
\end{tabular}

Fonte: Elaborado com base nos dados do IBGE/sites dos municípios. 
Identifica-se no Quadro 2 que se trata de municípios com populações variando de 2.382 a 15.409 e com colonização principalmente de origem alemã. Já os dados econômicos demonstram que a agropecuária prevalece como segmento econômico nos cinco municípios. O Produto Interno Bruto per capita varia de $\mathrm{R} \$ 15.549,96$ a $\mathrm{R} \$ 24.857,89$, revelando que os municípios apresentam indicadores do PIB dentro da média estadual.

No aspecto social, o Índice de Desenvolvimento Humano Municipal (IDHM) dos municípios pesquisados está dentro da média estadual, que foi em 2010 de 0,774.

Quanto à caracterização dos entrevistados da pesquisa o Quadro 3 expõe sua identificação.

Quadro 3 - Caracterização dos participantes da pesquisa

\begin{tabular}{|c|c|c|c|c|c|c|c|}
\hline $\begin{array}{c}\text { Entrevis- } \\
\text { tados }\end{array}$ & Idade & Gênero & $\begin{array}{l}\text { Formação: } \\
1 \text { - Graduação } \\
2 \text { - Especialização }\end{array}$ & $\begin{array}{l}\text { Tempo - } \\
\text { serviço } \\
\text { público } \\
\text { municipal }\end{array}$ & Cargo & $\begin{array}{c}\text { Tempo } \\
\text { no cargo }\end{array}$ & $\begin{array}{l}\text { Tempo } \\
\text { - coorde- } \\
\text { nador da } \\
\text { agenda }\end{array}$ \\
\hline$A$ & 39 & Masculino & $\begin{array}{l}1 \text { - Ciências Contá- } \\
\text { beis } \\
2 \text { - Finanças Públicas }\end{array}$ & 20 anos & Contador & 12 anos & 12 anos \\
\hline B & 46 & Feminino & $\begin{array}{l}1 \text { - Ciências } \\
\text { Contábeis } \\
2 \text { - Auditoria e Pe- } \\
\text { rícia }\end{array}$ & 21 anos & Contador & 10 anos & 10 anos \\
\hline C & 43 & Masculino & $\begin{array}{l}1 \text { - Matemática } \\
2 \text { - Controladoria } \\
\text { Pública }\end{array}$ & 22 anos & $\begin{array}{l}\text { Técnico de } \\
\text { Controle } \\
\text { Interno }\end{array}$ & 13 anos & 13 anos \\
\hline D & 44 & Masculino & $\begin{array}{l}\text { 1-Administração } \\
\text { 2-Gestão Financei- } \\
\text { ra/Controladoria }\end{array}$ & 7 anos & $\begin{array}{l}\text { Secretário } \\
\text { de Fazenda } \\
\text { e Planeja- } \\
\text { mento }\end{array}$ & 9 meses & 7 anos \\
\hline$E$ & 39 & Masculino & $\begin{array}{l}1 \text { - Matemática e } \\
\text { Física } \\
2 \text { - Matemática e } \\
\text { Física }\end{array}$ & 3 anos & $\begin{array}{l}\text { Secretário } \\
\text { de Admi- } \\
\text { nistração } \\
\text { em Finan- } \\
\text { ças }\end{array}$ & 3 anos & 3 anos \\
\hline
\end{tabular}

Fonte: Dados das entrevistas.

Percebe-se que os entrevistados apresentam características peculiares, podendo ser enquadrados em faixa etária e níveis de formação semelhantes. Trata-se em sua maioria de servidores de carreira com mais de 20 anos no serviço público municipal, assim como exercem a função de coordenador da agenda há mais de um mandato eletivo. Isso permite indagar: As práticas de construção das agendas governamentais são sempre conservadoras, mesmo com a mudança dos gestores?

\section{DESCRIÇÃO E INTERPRETAÇÃO DOS DADOS}

Nesse item são descritos os resultados quanto ao conhecimento e importância atribuída pelos entrevistados à agenda governamental. Na sequência é identificada a influência dos diferentes atores nas agendas midiática, pública e de políticas governamentais. No último tópico é identificado o fluxo das questões na elaboração da agenda governamental. 


\section{Conhecimento e importância da agenda governamental}

Nessa seção são apresentados os resultados dos questionamentos realizados quanto à conceituação de agenda governamental, sua importância e eventos que chamaram a atenção dos entrevistados durante o período em que estão à frente da coordenação das agendas, conforme evidenciado no Quadro 4.

Quadro 4 - Conhecimento e importância da agenda governamental (agenda-setting)

\begin{tabular}{|c|c|c|c|}
\hline $\begin{array}{l}\text { Entrevista- } \\
\quad \text { dos }\end{array}$ & $\begin{array}{l}\text { Conceito de agenda } \\
\text { governamental }\end{array}$ & $\begin{array}{l}\text { Importância que atri- } \\
\text { bui à agenda governa- } \\
\text { mental }\end{array}$ & $\begin{array}{l}\text { Eventos que chamaram atenção no } \\
\text { planejamento e instituição da agenda } \\
\text { governamental }\end{array}$ \\
\hline$A$ & $\begin{array}{l}\text { São as informações } \\
\text { necessárias para a } \\
\text { construção dos planos } \\
\text { governamentais. }\end{array}$ & $\begin{array}{c}\text { Grande importância, } \\
\text { mas os gestores não } \\
\text { estão preparados para } \\
\text { a construção adequa- } \\
\text { da. }\end{array}$ & $\begin{array}{l}\text { Inclusão como política pública munici- } \\
\text { pal da educação infantil de } 0 \text { a } 3 \text { anos } \\
\text { (creches) exigindo uma readequação do } \\
\text { planejamento com a nova demanda. }\end{array}$ \\
\hline B & $\begin{array}{l}\text { É o processo de } \\
\text { organização e } \\
\text { priorização das metas } \\
\text { e planos governamen- } \\
\text { tais. } \\
\end{array}$ & $\begin{array}{l}\text { É importante, pois } \\
\text { permite que se } \\
\text { definam as prioridades } \\
\text { do município. }\end{array}$ & $\begin{array}{c}\text { Eventos climáticos, em especial as es- } \\
\text { tiagens que exigem que sejam revistas } \\
\text { as prioridades para atender demandas } \\
\text { de água para a cidade e interior do } \\
\text { município. }\end{array}$ \\
\hline C & $\begin{array}{l}\text { É o processo de } \\
\text { elaboração das peças } \\
\text { de planejamento e } \\
\text { construções dos con- } \\
\text { selhos do município. }\end{array}$ & $\begin{array}{l}\text { É importante, pois } \\
\text { permite demonstrar o } \\
\text { que precisa ser feito e } \\
\text { o que de fato foi feito. }\end{array}$ & $\begin{array}{l}\text { Em } 2005 \text { o município utilizou o orça- } \\
\text { mento participativo que envolveu toda } \\
\text { a comunidade, mudando a sua visão } \\
\text { sobre administração pública. }\end{array}$ \\
\hline D & $\begin{array}{l}\text { Compreende a aquilo } \\
\text { que o governo propõe } \\
\text { em seu plano de go- } \\
\text { verno. }\end{array}$ & $\begin{array}{l}\text { Grande importância, } \\
\text { pois o planejamento } \\
\text { dos gestores muitas } \\
\text { vezes somente é de } \\
\text { curto prazo. }\end{array}$ & $\begin{array}{l}\text { Em } 2011 \text { foi elaborado o Plano Itapi- } \\
\text { ranga } 2030 \text { que permite uma visão de } \\
\text { longo prazo. }\end{array}$ \\
\hline$E$ & $\begin{array}{l}\text { Compreende o proces- } \\
\text { so de planejamento e } \\
\text { execução das políticas } \\
\text { públicas. }\end{array}$ & $\begin{array}{l}\text { Muito importante, } \\
\text { quando bem feito, o } \\
\text { planejamento e execu- } \\
\text { ção se tornam próxi- } \\
\text { mos ao ideal. }\end{array}$ & $\begin{array}{l}\text { As políticas públicas de responsabilida- } \\
\text { de dos governos federal e estadual, que } \\
\text { o município deve executar, sem receber } \\
\text { recursos suficientes para executá-las. }\end{array}$ \\
\hline
\end{tabular}

Fonte: Dados das entrevistas

Constata-se por meio do Quadro 4 que todos os entrevistados possuem um conceito semelhante do que é a agenda governamental, referindo-se ao conjunto de planos e metas do governo. Os conceitos apresentados pelos entrevistados vão ao encontro daquilo que é apresentado pelo arcabouço teórico, pois, conforme Kingdon (2003), a agenda governamental compreende o conjunto de aspectos que o governo e pessoas a ele ligadas concentram sua atenção num determinado momento.

No que se refere à compreensão da atribuição de importância à agenda governamental, todos os respondentes entendem como importante, permitindo a definição de prioridades e o que de fato foi posto em prática. Destacam também o despreparo dos gestores na construção adequada das agendas e sua visão de curto prazo do processo.

Quando questionados sobre eventos de destaque ocorridos ao longo dos anos em que são responsáveis pela condução do processo de elaboração das agendas, cada respondente destacou eventos pontuais que de alguma forma afetaram o planejamento, ou que mudaram a forma de constituição dos planos municipais. 
Os atores entrevistados e denominados por Viana (1996) como "alto staff!" da administração são responsáveis pelo processo de discussão, formulação dos planos e acompanham a sua instituição. Desse modo, a sua compreensão do conceito e importância da agenda governamental amplia a possibilidade de sucesso das agendas construídas. Constata-se que, mesmo com diferentes visões e perspectivas existe um conhecimento prévio do processo de elaboração da agenda, os eventos que as qualificam e sua influência nas ações governamentais.

\section{Influência na agenda midiática, pública e de políticas governamentais}

Nesta seção são apresentados os resultados da influência dos diversos atores nas diferentes agendas, compreendidas pela agenda midiática (media agenda-setting), agenda pública (public agenda-setting) e agenda de políticas governamentais (policy agenda-setting).

Inicialmente foram realizados questionamentos referentes à influência da mídia nas questões colocadas pelo público, políticos e governo, bem como o efeito inverso da influência desses atores sobre a mídia. Os resultados obtidos desses questionamentos são expostos no Quadro 5.

Quadro 5 - Influência da agenda midiática (media agenda-setting) no planejamento e instituição

\begin{tabular}{|c|c|c|c|c|c|}
\hline Atores & Mídia/Público & Mídia/Políticos & Mídia/Governo & Mídia/Governo & Mídia \\
\hline $\begin{array}{l}\text { Entrevis- } \\
\text { tados }\end{array}$ & $\begin{array}{l}\text { Influência da } \\
\text { mídia sobre o } \\
\text { público no pla- } \\
\text { nejamento }\end{array}$ & $\begin{array}{l}\text { Influência da } \\
\text { mídia sobre os } \\
\text { atores políticos } \\
\text { no planejamen- } \\
\text { to }\end{array}$ & $\begin{array}{l}\text { Influência da } \\
\text { mídia sobre o } \\
\text { governo no pla- } \\
\text { nejamento }\end{array}$ & $\begin{array}{c}\text { Influência da } \\
\text { mídia sobre o } \\
\text { governo na insti- } \\
\text { tuição }\end{array}$ & $\begin{array}{l}\text { Influência dos } \\
\text { atores na agen- } \\
\text { da midiática }\end{array}$ \\
\hline$A$ & $\begin{array}{c}\text { Não influencia, } \\
\text { pois o público } \\
\text { (comunidade) } \\
\text { tem pouca } \\
\text { participação } \\
\text { no processo de } \\
\text { planejamento. }\end{array}$ & $\begin{array}{l}\text { Sim - a mídia } \\
\text { divulga algo de } \\
\text { novo que deu } \\
\text { certo e isso } \\
\text { acaba sendo } \\
\text { colocado pelos } \\
\text { políticos. }\end{array}$ & $\begin{array}{l}\text { Sim - igual- } \\
\text { mente quando } \\
\text { algo de novo } \\
\text { é divulgado o } \\
\text { governo coloca } \\
\text { como uma nova } \\
\text { questão. }\end{array}$ & $\begin{array}{l}\text { Sim - influencia, } \\
\text { pois, quando é } \\
\text { possível ele ten- } \\
\text { ta copiar o que } \\
\text { os outros imple- } \\
\text { mentaram. }\end{array}$ & $\begin{array}{c}\text { O gestor in- } \\
\text { fluencia a mídia } \\
\text { e essa coloca a } \\
\text { questão para o } \\
\text { público (comu- } \\
\text { nidade). }\end{array}$ \\
\hline B & $\begin{array}{l}\text { Influencia mui- } \\
\text { to nas possíveis } \\
\text { questões que } \\
\text { a comunidade } \\
\text { pode colocar } \\
\text { como deman- } \\
\text { das. }\end{array}$ & $\begin{array}{l}\text { Influencia muito, } \\
\text { pois muitos se } \\
\text { utilizam daqui- } \\
\text { lo que a mídia } \\
\text { publica para se } \\
\text { promover politi- } \\
\text { camente. }\end{array}$ & $\begin{array}{l}\text { Não - o pla- } \\
\text { nejamento do } \\
\text { governo acaba } \\
\text { sendo muito } \\
\text { mais técnico do } \\
\text { que político. }\end{array}$ & $\begin{array}{l}\text { Sim - pois co- } \\
\text { loca o que foi } \\
\text { planejado e não } \\
\text { foi executado, } \\
\text { exigindo uma } \\
\text { mudança pelo } \\
\text { governo. }\end{array}$ & $\begin{array}{l}\text { Somente se a } \\
\text { mídia sentir } \\
\text { interesse em ser } \\
\text { influenciada. }\end{array}$ \\
\hline C & Pouco. & Pouco. & Pouco. & Pouco. & $\begin{array}{l}\text { Principalmente } \\
\text { pelas ONGs } \\
\text { sobre políticas } \\
\text { demandadas. }\end{array}$ \\
\hline $\mathrm{D}$ & $\begin{array}{l}\text { Sim, às vezes é } \\
\text { difícil de ver o } \\
\text { que é questão } \\
\text { do público e de } \\
\text { grupos em fun- } \\
\text { ção da mídia. }\end{array}$ & $\begin{array}{c}\text { Influencia muito, } \\
\text { pois pode me- } \\
\text { lhorar sua ima- } \\
\text { gem ou deixá-los } \\
\text { de lado. }\end{array}$ & $\begin{array}{l}\text { Pouco. Auxilia } \\
\text { mais na divulga- } \\
\text { ção positiva das } \\
\text { questões. }\end{array}$ & $\begin{array}{c}\text { Pouco. Mas, } \\
\text { auxilia na corre- } \\
\text { ta efetivação das } \\
\text { questões. }\end{array}$ & $\begin{array}{c}\text { Existe, pois a } \\
\text { mídia acaba } \\
\text { “comprando a } \\
\text { ideia" do gestor } \\
\text { e divulgando } \\
\text { para a comuni- } \\
\text { dade. }\end{array}$ \\
\hline
\end{tabular}




\begin{tabular}{|c|c|c|c|c|c|}
\hline \multirow{4}{*}{$\mathrm{E}$} & $\begin{array}{c}\text { Influencia, } \\
\text { pois interfere } \\
\text { naquilo que a } \\
\text { comunidade } \\
\text { sente como } \\
\text { necessidades } \\
\text { e apresenta } \\
\text { como deman- } \\
\text { das. }\end{array}$ & $\begin{array}{c}\text { Um pequeno } \\
\text { percentual. }\end{array}$ & $\begin{array}{c}\text { Pouco. Pois no } \\
\text { planejamento } \\
\text { parte-se da } \\
\text { demanda conhe- } \\
\text { cida e recursos } \\
\text { disponíveis. }\end{array}$ & $\begin{array}{c}\text { Um pouco. Pois } \\
\text { se o planejamen- } \\
\text { to foi bem- feito } \\
\text { a execução se- } \\
\text { guirá no mesmo } \\
\text { sentido. }\end{array}$ & $\begin{array}{c}\text { Influencia, sen- } \\
\text { do que cada } \\
\text { ator buscará } \\
\text { colocar a sua } \\
\text { posição para } \\
\text { mídia e assim } \\
\text { influenciar a sua } \\
\text { agenda, o que é } \\
\text { interessante. }\end{array}$ \\
& & & & & \\
\hline
\end{tabular}

Fonte: Dados das entrevistas.

De acordo com Capella (2005), a agenda-setting é o processo de competição de ideias para ganhar espaço perante a mídia, o público e os altos escalões governamentais. Nesse sentido, o Quadro 5 demonstra que as questões apresentadas pelo público (comunidade) para inclusão na agenda são influenciadas pela mídia na maioria dos municípios pesquisados. Nos municípios em que é menos influente isso é reflexo, principalmente, da baixa participação popular no processo de planejamento.

No tocante à influência da mídia sobre as questões apresentadas pelos atores políticos (vereadores, partidos, filiados, entre outros), existe uma interferência significativa. Isso ocorre principalmente devido a esses atores estarem sempre preocupados com sua imagem perante o público, buscam apresentar o que a mídia divulga como novas políticas públicas e que deverão ser prioridade no planejamento e instituição.

No que se refere à influência midiática sobre o governo nas fases de planejamento e instalação, percebe-se que na maioria dos municípios há pouca influência. Naqueles em que ocorre interferência maior da agência midiática, esta é voltada à cobrança de políticas novas praticadas em outros municípios, ou que foram planejadas e ainda não executadas.

Quando questionados sobre a influência dos diversos atores sobre a agenda midiática, verificou-se que ela existe e de diversas formas, principalmente pelas entidades e governo. Destaca-se que essa influência não necessariamente é negativa, pois muitas vezes a mídia deseja ser influenciada, o que permite a divulgação adequada dos processos de construção e prática da agenda governamental.

A influência da mídia demonstrada nos resultados sobre os atores políticos, público e o próprio governo remete-nos a um conjunto de questionamentos que merecem ser destacados: a) As demandas apresentadas pelo público são de fato aquelas que a comunidade tem e que interferem na sua qualidade de vida?; b) As demandas apresentas pelos atores políticos são efetivamente aquelas que nascem da comunidade, são avaliadas pelos políticos e apresentadas na agenda?; c) O planejamento e execução das políticas vão ao encontro daquilo que foi apresentado pela comunidade e pelos atores políticos?; d) A influência dos diferentes atores sobre a mídia é positiva no processo de definição das políticas planejadas e postas em prática? Esse processo de influência dos diferentes atores sobre a mídia e de forma recíproca carece de cuidado especial na definição de prioridades. Se por um lado ela é capaz de motivar a participação dos diversos atores na elaboração da agenda governamental, por outro, as prioridades apresentadas pelos atores podem estar "viciadas" a partir da forte influência midiática. 
No Quadro 6 são apresentadas as questões mais importantes, assim como atores e eventos que interferem na agenda pública.

Quadro 6 - Influência da agenda pública (public agenda-setting) no planejamento e instituição

\begin{tabular}{|c|c|c|c|c|}
\hline Atores & $\begin{array}{l}\text { Público (comuni- } \\
\text { dade) }\end{array}$ & $\begin{array}{l}\text { Público (comuni- } \\
\text { dade) }\end{array}$ & $\begin{array}{l}\text { Público (comuni- } \\
\text { dade) }\end{array}$ & $\begin{array}{c}\text { Público (comunida- } \\
\text { de) }\end{array}$ \\
\hline $\begin{array}{l}\text { Entrevista- } \\
\text { dos }\end{array}$ & $\begin{array}{c}\text { O que influencia as } \\
\text { questões do público } \\
\text { no planejamento }\end{array}$ & $\begin{array}{c}\text { Questões mais } \\
\text { importantes para o } \\
\text { público no planeja- } \\
\text { mento }\end{array}$ & $\begin{array}{l}\text { Mudanças das } \\
\text { questões pelo pú- } \\
\text { blico na efetivação }\end{array}$ & $\begin{array}{l}\text { Atores que influen- } \\
\text { ciam nas questões do } \\
\text { público }\end{array}$ \\
\hline$A$ & $\begin{array}{c}\text { Aquilo que o público } \\
\text { precisa de imedia- } \\
\text { to, nada de longo } \\
\text { prazo. }\end{array}$ & $\begin{array}{l}\text { Cada segmento } \\
\text { coloca as questões } \\
\text { suas e não de toda } \\
\text { a comunidade. }\end{array}$ & $\begin{array}{c}\text { A demanda muitas } \\
\text { vezes se altera, devi- } \\
\text { do às necessidades } \\
\text { do momento terem } \\
\text { mudado. }\end{array}$ & $\begin{array}{c}\text { A mídia, o governo } \\
\text { e demais atores in- } \\
\text { fluenciam, mas me- } \\
\text { nos que a economia } \\
\text { e as necessidades do } \\
\text { momento. }\end{array}$ \\
\hline B & $\begin{array}{c}\text { A prioridade por } \\
\text { alguma política es- } \\
\text { pecífica. }\end{array}$ & $\begin{array}{c}\text { Aquilo que é mais } \\
\text { importante para ela } \\
\text { no momento. }\end{array}$ & $\begin{array}{l}\text { A mudança das } \\
\text { questões é induzida } \\
\text { pelo governo devido } \\
\text { à mudança de cená- } \\
\text { rios até o momento } \\
\text { da execução. }\end{array}$ & $\begin{array}{c}\text { Os políticos influen- } \\
\text { ciam de tal forma que } \\
\text { induzem a comunida- } \\
\text { de definindo o que é } \\
\text { mais importante para } \\
\text { ela. }\end{array}$ \\
\hline C & $\begin{array}{l}\text { A prioridade por } \\
\text { alguma política } \\
\text { específica de um } \\
\text { grupo. }\end{array}$ & $\begin{array}{c}\text { Além da saúde que } \\
\text { é prioridade, cada } \\
\text { segmento coloca a } \\
\text { sua prioridade indi- } \\
\text { vidual. }\end{array}$ & $\begin{array}{l}\text { As questões perma- } \\
\text { necem as mesmas. }\end{array}$ & $\begin{array}{c}\text { Os líderes da comu- } \\
\text { nidade. }\end{array}$ \\
\hline D & $\begin{array}{l}\text { A comunidade as- } \\
\text { sume as questões } \\
\text { que o poder público } \\
\text { coloca como impor- } \\
\text { tantes. Existe muito } \\
\text { imediatismo. }\end{array}$ & $\begin{array}{l}\text { Além da cultura e } \\
\text { esporte, as demais } \\
\text { prioridades são por } \\
\text { segmento. }\end{array}$ & $\begin{array}{l}\text { Poucas mudam, em } \\
\text { função de discus- } \\
\text { sões mais amplas na } \\
\text { comunidade. }\end{array}$ & $\begin{array}{l}\text { Os políticos que aca- } \\
\text { bam direcionando as } \\
\text { políticas em função } \\
\text { de sua vinculação } \\
\text { financeira (Ex: emen- } \\
\text { das parlamentares). }\end{array}$ \\
\hline$E$ & $\begin{array}{l}\text { As questões de inte- } \\
\text { resse de determina- } \\
\text { dos setores. }\end{array}$ & $\begin{array}{c}\text { A importância da } \\
\text { saúde e infraestru- } \\
\text { tura. }\end{array}$ & $\begin{array}{l}\text { Algumas mudam, } \\
\text { em função de exi- } \\
\text { gências legais e falta } \\
\text { de recursos. }\end{array}$ & $\begin{array}{c}\text { Os secretários, verea- } \\
\text { dores, líderes comu- } \\
\text { nitários e conselhos } \\
\text { municipais. }\end{array}$ \\
\hline
\end{tabular}

Fonte: Dados das entrevistas.

Referindo-se ao processo de construção das agendas, Capella (2004) destaca que as questões emergentes na agenda midiática influenciam diretamente a pública, com abrangência também na governamental. Posteriormente, os temas da agenda pública se materializam na governamental e provocam efeitos na midiática. Finalmente questões geradas na agenda governamental exercem influência na mídiática e na pública.

Concernente às questões da agenda pública mostradas no Quadro 6, percebe-se que a influência nas questões apresentadas pelo público são as demandas imediatas e políticas específicas para determinado grupo ou setor. Quanto às questões mais importantes na fase do planejamento, merecem destaque aquelas que atendem determinado segmento da comunidade, assim como as políticas públicas que são demandadas pela comunidade, como as de saúde, cultura, esporte e infraestrutura. 
No que se refere à mudança das questões no período de instalação das políticas, percebe-se que a alteração deve-se em razão de mudanças legais, falta de recursos, alteração de cenários econômicos e eventos imprevistos que assumem a prioridade no seu estabelecimento.

Entre os atores que mais influenciam as questões apresentadas pelo público estão os políticos, lideranças, conselhos municipais, a mídia e finalmente o governo. Constata-se que no momento da definição das questões por parte da comunidade vários atores são mais influentes que a mídia. Esse cenário justifica-se também por se tratar de pequenos municípios, em que existe maior proximidade dos diversos atores com a comunidade.

No Quadro 7 são apresentados os eventos e atores que influenciam a agenda de políticas governamentais no período de planejamento e prática das políticas públicas.

Quadro 7 - Influência da agenda de políticas governamentais (policy agenda-setting) no planejamento e sua prática

\begin{tabular}{|c|c|c|c|}
\hline Atores & $\begin{array}{l}\text { Governo (prefeito/ } \\
\text { secretários) }\end{array}$ & $\begin{array}{c}\text { Governo } \\
\text { (prefeito/secretários) }\end{array}$ & $\begin{array}{c}\text { Governo (prefeito/secretá- } \\
\text { rios) }\end{array}$ \\
\hline $\begin{array}{l}\text { Entrevista- } \\
\text { dos }\end{array}$ & $\begin{array}{l}\text { Eventos que influen- } \\
\text { ciam o governo no } \\
\text { planejamento }\end{array}$ & $\begin{array}{l}\text { Eventos que influenciam o } \\
\text { governo na instituição }\end{array}$ & $\begin{array}{c}\text { Atores que influenciam o } \\
\text { governo no planejamento e } \\
\text { efetivação }\end{array}$ \\
\hline A & $\begin{array}{l}\text { A agenda política (elei- } \\
\text { toral). }\end{array}$ & $\begin{array}{l}\text { A influência financeira e a polí- } \\
\text { tica (eleitoral). }\end{array}$ & $\begin{array}{c}\text { Atores que trouxerem re- } \\
\text { sultados políticos positivos } \\
\text { para o gestor. }\end{array}$ \\
\hline B & Os limites legais. & $\begin{array}{l}\text { A judicialização das políticas } \\
\text { públicas que não observam o } \\
\text { planejamento. }\end{array}$ & Judiciário e atores políticos. \\
\hline $\mathrm{C}$ & $\begin{array}{l}\text { A agenda política (elei- } \\
\text { toral). }\end{array}$ & $\begin{array}{l}\text { A influência financeira da frus- } \\
\text { tração das receitas previstas } \\
\text { (principalmente recursos vin- } \\
\text { culados). }\end{array}$ & $\begin{array}{l}\text { Todos os atores que contri- } \\
\text { buíram na construção do } \\
\text { Plano de Governo. }\end{array}$ \\
\hline $\mathrm{D}$ & $\begin{array}{l}\text { O desejo da comuni- } \\
\text { dade. }\end{array}$ & $\begin{array}{l}\text { A influência financeira da frus- } \\
\text { tração das receitas previstas. }\end{array}$ & $\begin{array}{l}\text { Conselhos municipais que } \\
\text { representam os mais diver- } \\
\text { sos segmentos. }\end{array}$ \\
\hline $\mathrm{E}$ & $\begin{array}{l}\text { As políticas originadas } \\
\text { das esferas estadual e } \\
\text { federal. }\end{array}$ & $\begin{array}{l}\text { Eventos não passíveis de pre- } \\
\text { visão. }\end{array}$ & $\begin{array}{c}\text { Colegiado de secretários } \\
\text { municipais. }\end{array}$ \\
\hline
\end{tabular}

Fonte: Dados das entrevistas.

Por meio do Quadro 7 percebe-se que alguns eventos merecem destaque quanto a sua influência no processo de planejamento e colocação em prática das políticas governamentais. No que se refere ao período de planejamento, a agenda política eleitoral dos diferentes atores afeta significativamente a construção da agenda de políticas governamentais. De outro modo, na fase de instauração das políticas, a frustração na arrecadação de recursos, judicialização das políticas e eventos imprevisíveis são os que mais influenciam a agenda governamental.

Quanto aos atores mais importantes que influenciam o governo no planejamento e instituição, foram citados os mais diversos, como os atores políticos, conselhos municipais, secretários municipais, Judiciário e demais atores que participam da construção dos planos governamentais. 
Constata-se que existe uma distância significativa entre a agenda de políticas governamentais no planejamento e prática das ações governamentais. Esse cenário desmotiva os diversos atores no processo de construção da agenda governamental, pois frustra as expectativas e amplia o sentimento de pouca importância das questões da comunidade no planejamento e principalmente instalação de políticas públicas locais.

\section{Modelo dos múltiplos fluxos de Kingdon na construção da agenda gover- namental}

Para compreender o processo de elaboração das questões que integrarão a agenda governamental, utilizou-se o modelo dos múltiplos fluxos de Kingdon, sendo aplicadas seis questões na mesma ordem do modelo, conforme apresentado no Quadro 8.

Quadro 8 - Fluxo das questões para construção da agenda governamental (governmental agenda)

\begin{tabular}{|c|c|c|c|c|c|c|}
\hline $\begin{array}{l}\text { Entrevis- } \\
\text { tados }\end{array}$ & $\begin{array}{l}\text { Competição } \\
\text { das questões }\end{array}$ & $\begin{array}{c}\text { Sucesso e } \\
\text { insucesso das } \\
\text { questões }\end{array}$ & $\begin{array}{l}\text { Necessidade } \\
\text { da com- } \\
\text { preensão da } \\
\text { questão como } \\
\text { problema }\end{array}$ & $\begin{array}{c}\text { Soluções } \\
\text { para os } \\
\text { problemas } \\
\text { como fato- } \\
\text { res decisi- } \\
\text { vos }\end{array}$ & $\begin{array}{l}\text { Barganhas } \\
\text { políticas } \\
\text { como fato- } \\
\text { res decisivos }\end{array}$ & $\begin{array}{l}\text { Fluxo político } \\
\text { como fator de } \\
\text { influência }\end{array}$ \\
\hline$A$ & $\begin{array}{c}\text { Existe compe- } \\
\text { tição de ideias } \\
\text { entre diferen- } \\
\text { tes setores da } \\
\text { administração } \\
\text { pública. }\end{array}$ & $\begin{array}{c}\text { A forma de } \\
\text { formulação das } \\
\text { políticas pelo } \\
\text { gestor secun- } \\
\text { dário (secretá- } \\
\text { rio). }\end{array}$ & $\begin{array}{l}\text { Quando a } \\
\text { questão } \\
\text { atinge mais } \\
\text { gestores } \\
\text { secundários } \\
\text { (secretários), } \\
\text { quando é mais } \\
\text { ampla. }\end{array}$ & $\begin{array}{l}\text { Quando as } \\
\text { soluções } \\
\text { atendem } \\
\text { da mesma } \\
\text { forma } \\
\text { um grupo } \\
\text { maior de } \\
\text { interesse. }\end{array}$ & $\begin{array}{l}\text { Existem as } \\
\text { barganhas } \\
\text { e se cria } \\
\text { muitas vezes } \\
\text { prioridades } \\
\text { em função } \\
\text { delas. }\end{array}$ & $\begin{array}{l}\text { Existe uma influên- } \\
\text { cia de grupos de } \\
\text { poder, quando eles } \\
\text { mudam, mudam as } \\
\text { prioridades. }\end{array}$ \\
\hline B & $\begin{array}{l}\text { Existe pouca } \\
\text { disputa, as } \\
\text { prioridades } \\
\text { gerais prevale- } \\
\text { cem. }\end{array}$ & $\begin{array}{l}\text { A visão daquilo } \\
\text { que é mais } \\
\text { importante } \\
\text { para toda so- } \\
\text { ciedade. }\end{array}$ & $\begin{array}{l}\text { Pela necessi- } \\
\text { dade da cole- } \\
\text { tividade. }\end{array}$ & $\begin{array}{l}\text { Quando as } \\
\text { soluções } \\
\text { são impor- } \\
\text { tantes para } \\
\text { a coletivi- } \\
\text { dade. }\end{array}$ & $\begin{array}{l}\text { A barganha } \\
\text { é mais pela } \\
\text { necessidade } \\
\text { que interes- } \\
\text { se político. }\end{array}$ & $\begin{array}{l}\text { Existe influência, } \\
\text { especialmente na } \\
\text { mudança de gover- } \\
\text { no, que tem outras } \\
\text { prioridades. }\end{array}$ \\
\hline C & $\begin{array}{l}\text { Existe pouca, } \\
\text { pois, as prio- } \\
\text { ridades são } \\
\text { semelhantes. }\end{array}$ & $\begin{array}{l}\text { Questões que } \\
\text { não podem ser } \\
\text { executadas. }\end{array}$ & $\begin{array}{l}\text { Tem como } \\
\text { prioridade se } \\
\text { for compreen- } \\
\text { dida como um } \\
\text { problema. }\end{array}$ & $\begin{array}{l}\text { Se tiver } \\
\text { solução a } \\
\text { questão } \\
\text { terá priori- } \\
\text { dade. }\end{array}$ & $\begin{array}{l}\text { Existe pouca } \\
\text { barganha de } \\
\text { interesses. }\end{array}$ & $\begin{array}{l}\text { Existe influência, } \\
\text { principalmente } \\
\text { na mudança de } \\
\text { governo pelo des- } \\
\text { conhecimento dos } \\
\text { gestores. }\end{array}$ \\
\hline$D$ & $\begin{array}{l}\text { Existe em } \\
\text { alguns setores } \\
\text { em que tem } \\
\text { disputas por } \\
\text { prioridades. }\end{array}$ & $\begin{array}{l}\text { Disponibilida- } \\
\text { de de recurso } \\
\text { financeiro ou } \\
\text { de recursos } \\
\text { humanos. }\end{array}$ & $\begin{array}{c}\text { Quando vier } \\
\text { da demanda } \\
\text { da comuni- } \\
\text { dade. }\end{array}$ & $\begin{array}{c}\text { Quando a } \\
\text { solução já } \\
\text { existe sem } \\
\text { dependên- } \\
\text { cia finan- } \\
\text { ceira, terá } \\
\text { prioridade. }\end{array}$ & $\begin{array}{l}\text { Existe pouca } \\
\text { barganha, } \\
\text { somente } \\
\text { pequenas } \\
\text { questões } \\
\text { pontuais. }\end{array}$ & $\begin{array}{c}\text { Existe influência, } \\
\text { com o Conselho de } \\
\text { Desenvolvimento } \\
\text { Econômico, man- } \\
\text { tém-se o que foi } \\
\text { planejado a longo } \\
\text { prazo. }\end{array}$ \\
\hline$E$ & $\begin{array}{l}\text { Existe, porque } \\
\text { a demanda é } \\
\text { maior do que } \\
\text { a capacidade } \\
\text { de execução.. }\end{array}$ & $\begin{array}{c}\text { A força dos } \\
\text { atores. }\end{array}$ & $\begin{array}{l}\text { Não necessa- } \\
\text { riamente, mas } \\
\text { a maioria vem } \\
\text { de um proble- } \\
\text { ma que será } \\
\text { solucionado } \\
\text { com uma polí- } \\
\text { tica pública. }\end{array}$ & $\begin{array}{l}\text { Se tiver a } \\
\text { solução a } \\
\text { questão } \\
\text { terá priori- } \\
\text { dade, de- } \\
\text { pendendo } \\
\text { também da } \\
\text { sua gravi- } \\
\text { dade. }\end{array}$ & $\begin{array}{l}\text { Existe pou- } \\
\text { co, devido à } \\
\text { proximidade } \\
\text { da comuni- } \\
\text { dade com os } \\
\text { gestores. }\end{array}$ & $\begin{array}{l}\text { Existe influência, } \\
\text { pois cada governo } \\
\text { tem sua agenda, } \\
\text { mesmo tendo po- } \\
\text { líticas públicas de } \\
\text { Estado. Depende } \\
\text { de cada gover- } \\
\text { nante. }\end{array}$ \\
\hline
\end{tabular}

Fonte: Dados das entrevistas. 
De acordo com Capella (2004), a ideia central do modelo de Kingdon "é de que alguns atores são influentes na definição da agenda governamental (governmental agenda), enquanto outros exercem maior influência na definição das alternativas (decision agenda)".

Diante disso, o Quadro 8 reflete inicialmente que a competição de ideias ocorre somente em alguns cenários entre os diferentes setores da comunidade, prevalecendo as questões que são centrais para os participantes do processo e que privilegiam a todos, uma vez que as demandas são maiores que a capacidade de execução.

De outra forma, as questões terão sucesso ou insucesso por diversos fatores, como sua forma de elaboração, serem importantes a todos, a força dos atores que as apresentam, serem passíveis de colocar em prática e a disponibilidade de recursos financeiros e humanos.

O fato da compreensão da questão como um problema (problem stream) priorizará a sua resolução, necessitando, portanto, ser assim interpretada por vários gestores, ser uma necessidade coletiva e se originar da demanda da comunidade. Quando as questões são acompanhadas de possíveis soluções (policy stream), terão prioridade para a resolução, assim como dependendo da sua gravidade e quando representam uma solução para grupos ou coletividade.

No tocante às barganhas políticas para a inclusão de questões na agenda, percebe-se que em alguns municípios elas são significativas para beneficiar os agentes em suas demandas políticas eleitorais. De outra forma, em outros, são menos presentes, devido à proximidade dos gestores com a comunidade. Quando ocorrem, têm como objetivo a solução de pequenas demandas pontuais da comunidade e pleiteadas pelos políticos.

Finalizando, a coleta dos dados buscou o questionamento no sentido do fluxo político (political stream). Foi consenso nos municípios pesquisados a influência desse fluxo na construção da agenda governamental. Destaca-se que as prioridades mudam de acordo com os grupos de poder e mudanças de governo. De outra forma, percebe-se que determinados municípios buscam alternativas para evitar esse excesso de influência, por meio de definição de metas a longo prazo pelos Conselhos Municipais de Desenvolvimento e preservação das políticas de Estado sobre as políticas de governo.

Percebe-se que o fluxo das questões para a construção da agenda governamental passa por competições, barganhas e influências. Trata-se de um processo natural, mais ou menos intenso de acordo com as demandas existentes e que diferem em cada município. Quando essa disputa ocorre dentro do campo das discussões e debates é saudável para qualificar as futuras políticas públicas a serem instaladas. De outro modo, quando as barganhas e influências políticas ultrapassam o marco do processo democrático de escolha de prioridades, torna-se extremamente prejudicial na aplicação de recursos e execução de políticas locais. Percebe-se no estudo que em alguns municípios esses tipos de barganhas e influências negativas existem e interferem na construção das agendas. 


\section{CONCLUSÕES}

$\mathrm{O}$ artigo teve como objetivo geral descrever a influência dos diferentes eventos, atores e questões na construção da agenda dos municípios integrantes da região de abrangência da 31a Secretaria de Desenvolvimento Regional (SDR) de Itapiranga - SC. Para atingir o objetivo geral proposto no artigo foi aplicada a metodologia exploratória e descritiva, utilizando-se como procedimento o levantamento com abordagem qualitativa. Os dados foram coletados por meio de entrevistas estruturadas junto aos responsáveis pela coordenação da agenda governamental dos municípios investigados.

Inicialmente foi realizada a identificação e caracterização dos municípios integrantes da 31a SDR de Itapiranga - SC, assim como os respondentes da pesquisa. Trata-se de cinco municípios com predominância da colonização alemã, com base econômica na agropecuária e com indicadores sociais satisfatórios quando comparados com o restante do Estado. Quanto aos respondentes, de modo geral, possuem níveis de formação semelhante, com predominância do gênero masculino e responsáveis pela agenda em sua maioria há mais de uma gestão.

Em seguida foram questionados quanto à importância da agenda e fatos relevantes ocorridos no processo de sua construção. A maioria considera a agenda importante no processo de definição e execução de prioridades. No que se refere a eventos de destaque na elaboração das agendas, são lembrados eventos pontuais que de alguma forma afetaram a construção dos planos nos municípios. A compreensão do conceito e da importância da agenda governamental pelos respondentes amplia as chances de sucesso no planejamento e execução, pois são os responsáveis pela condução do processo de construção da agenda.

Referente à influência midiática, infere-se que na maioria dos municípios existe algum tipo de influência da mídia sobre o público, atores políticos ou o próprio governo. Da mesma forma, existe a influência dos diversos atores sobre a agenda midiática. Destaca-se nesse ponto a necessidade de reflexão por parte dos diversos atores envolvidos na construção da agenda governamental quanto à influência dos atores sobre a mídia e inversamente. Essa influência em alguns aspectos pode ser positiva e em outros extremamente danosa ao processo.

Por outro lado, conclui-se que as demandas apresentadas pelo público são guiadas pelo imediatismo, setorizadas ou segmentadas e as demandas estruturantes são as políticas universais, como a saúde. Fatores como falta de recursos, aspectos legais e cenários econômicos influenciam nas demandas que serão efetivadas. Atores como políticos, lideranças, mídia e governo são os mais influentes nas questões apresentadas pelo público. Esse comportamento na escolha das prioridades e influência maior de alguns atores remete fortemente à realidade desses municípios, compreendidos como de pequeno porte.

No tocante à agenda de políticas governamentais, esta é influenciada por eventos como frustrações de receitas, judicialização de políticas, agenda eleitoral, entre outros. Essa agenda é influenciada por diversos atores, como os políticos, conselhos municipais, secretários, poder Judiciário e demais atores que participam da elaboração dos planos 
governamentais. O cuidado necessário para que a agenda de políticas públicas planejadas não se distancie das políticas praticadas é fundamental para não frustrar os participantes do processo de elaboração.

Finalmente, o fluxo das questões na construção da agenda governamental demonstra que a competição entre as questões existe somente em alguns cenários. De outro modo, o sucesso das questões depende basicamente da força dos atores que as apresentam e disponibilidade de recursos. A necessidade de compreender a questão como um problema é importante para que seja priorizada, assim como se for acompanhada por possíveis soluções. As barganhas políticas nos municípios existem, mas não são muito significativas na definição das questões na agenda. Da mesma forma, o fluxo político é importante na construção da agenda governamental. Destaca-se que as barganhas e competições são naturais na construção da agenda governamental, no entanto deve limitar-se ao ambiente democrático de escolha de prioridades, qualificando as futuras políticas públicas a serem postas em prática.

Desse modo, diante do pressuposto da pesquisa conclui-se que existe uma influência dos diferentes eventos e atores sobre as questões e agendas. Por outro lado, ocorre a influência da mídia sobre o planejamento e execução das políticas públicas. Assim, torna-se importante rever alguns aspectos do processo de elaboração da agenda governamental, voltando o olhar especialmente para a influência significativa de alguns atores e da mídia para que seja preservado o ambiente de competição saudável no planejamento e instituição das políticas públicas.

Os resultados satisfatórios desse estudo exploratório permitirão um desdobramento com nova linha de investigação, mais analítica e aprofundada. Para isso torna-se necessário estabelecer uma hipótese de que os diferentes eventos, atores e questões interferem positivamente na agenda governamental e consequentemente nos índices de desenvolvimento local.

\section{REFERÊNCIAS}

ARRETCHE, Marta T. S. "Políticas sociais no Brasil: descentralização em um Estado federativo." Revista brasileira de ciências sociais, v.14, n.40 (1999): 111-141.

BAUMGARTNER, Frank R.; JONES, Bryan D. (1993) Agendas and Instability in American Politics. Chicago: University of Chicago Press.

BOISIER, S. Sociedad del conocimiento. Conocimiento social y gestión territorial. In.: BECKER, D. F.; BANDEIRA, P. S. (org.) Desenvolvimento local-regional (vol. 2). S. Cruz do Sul: Edunisc, 2000. p. 15-68.

CAPELLA, Ana Cláudia Niedhardt. O processo de agenda-setting na reforma da administração pública (1995-2002). 2004. 243 f. Tese (Doutorado em Ciências Sociais) - Programa de Pós-graduação do Centro de Educação e Ciências Humanas da Universidade Federal de São Carlos.

Formação da Agenda Governamental: Perspectivas Teóricas. In: XXIX Encontro Anual da ANPOCS. 25 a 29 de outubro de 2005, Caxambu, MG. Disponível em: http://www.anpocs.org/portal/index.php?option=com_docman\&task=doc_view\&gid=3789\&Itemid=318. Acesso em: 06 out. 2015.COBB, W. Roger; ELDER, V. Charles. The politics of agenda building: an a1temative perspective for modem democratic theory. Journal of Politics, 33, 1971.

COHEN, Michael, MARCH, James; OLSEN, Johan. "A Garbage Can Model of Organizational Choice", Administrative Science Quarterley. 17: 1-25. 1972.

COSTA FILHO, Orlando Sabino da; REZENDE, Sonaly Cristina. O saneamento na agenda pública: a dinâmica política e implantação dos serviços em Rio Branco - Acre. Revista Brasileira de Gestão e Desenvolvimento Regional, v. 12, n. 1, p. 331-354, 2016. 
COSTA, Marcelo Marchesini da. Formação da agenda governamental: as políticas públicas de economia solidária no Brasil e na Venezuela. 2008. 131 f. Dissertação (Mestrado em Administração) - Programa de Pós-graduação em Administração da Faculdade de Economia, Administração, Contabilidade e Ciências da Informação e Documentação da Universidade de Brasília.

FREY, Klaus. Políticas públicas: um debate conceitual e reflexões referentes à prática da análise de políticas públicas no Brasil. Revista Planejamento e Políticas Públicas, n. 21, p. 211-259, 2000.

GIL, Antônio Carlos. Como elaborar projetos de pesquisa. 4. ed. São Paulo: Atlas, 2002.

GOTTEMS, Leila Bernarda Donato et al. O modelo dos fluxos de Kingdon na análise de políticas de saúde: aplicabilidades, contribuições e limites. Revista Saúde e Sociedade, v.22, n. 2, p. 511-520, 2013.

HOFFERBERT, Richard. The study of public policy. Nova York, Merril, 1974.

KINGDON, John. (2003) [1984]. Agendas, Alternatives, and Public Policies. 3a. Ed. Nova York: Harper Collins.

LAKATOS, Eva Maria; MARCONI, Marina de Andrade. Metodologia do trabalho científico: procedimentos básicos, pesquisa bibliográfica, projeto e relatório, publicações e trabalhos científicos. 4. ed. São Paulo: Atlas, 1992.

PINTO, Isabela Cardoso M. Construção da agenda governamental: atores, arenas e processo decisório na saúde. Revista de Organizações \& Sociedade, v.15, n.44, p. 13-23, 2008.

RAUPP, Fabiano Maury. BEUREN, Ilse Maria. Caracterização da pesquisa em Contabilidade. In. BEUREN, Ilse Maria (Org). Como elaborar trabalhos monográficos em contabilidade: teoria e prática. 2. ed. São Paulo: Atlas, 2004.

RICHARDSON, R. J. Pesquisa social: métodos e técnicas. 2. ed. São Paulo: Atlas, 1989.

ROSSETTO, Graça Penha Nascimento; SILVA, Alberto Marques. Agenda-setting e Framing. Detalhes de uma mesma teoria? Revista Intexto, n. 26, p. 98-114, 2012.

SILVA, Christian Luiz da; BASSI, Nadia Solange Schmidt. Políticas públicas e desenvolvimento local. In. SILVA, Christian Luiz da (Org). Políticas públicas e desenvolvimento local: instrumentos e proposições de análise para o Brasil. Petrópolis, RJ: Vozes, 2012.

SOUZA, Celina. Políticas púbicas: uma revisão da literatura. Revista Sociologias, ano 8, n. 16, p. 20-45, 2006.

VIANA, Ana Luiza. Abordagens metodológicas em políticas públicas. Revista de Administração Pública, v. 30, n. 2, p. 5-43, 1996.

WEEgE, S. A. Política Pública de Saúde e Desenvolvimento Regional: uma avaliação do financiamento do Sistema Único de Saúde dos Municípios de Apiúna, Timbó e Blumenau em razão dos pressupostos da organização da Política Pública de Saúde. 2012. 189 f. Dissertação (Mestrado em Desenvolvimento Regional) - Programa de Pós - Graduação em Desenvolvimento Regional do Centro de Ciências Humanas e da Comunicação da Universidade Regional de Blumenau - Furb. 